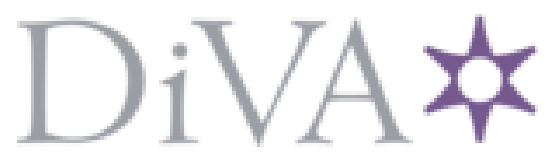

http://www.diva-portal.org

\title{
Postprint
}

This is the accepted version of a paper published in Clinical Chemistry and Laboratory Medicine. This paper has been peer-reviewed but does not include the final publisher proof-corrections or journal pagination.

Citation for the original published paper (version of record):

Bölenius, K., Söderberg, J., Hultdin, J., Lindkvist, M., Brulin, C. et al. (2013)

Minor improvement of venous blood specimen collection practices in primary health care after a large-scale educational intervention.

Clinical Chemistry and Laboratory Medicine, 51(2): 303-310

http://dx.doi.org/10.1515/cclm-2012-0159

Access to the published version may require subscription.

N.B. When citing this work, cite the original published paper.

Permanent link to this version:

http://urn.kb.se/resolve?urn=urn:nbn:se:umu:diva-61551 


\section{Minor improvement of venous blood specimen collection practices in primary health care after a large-scale educational intervention}

\section{Karin Bölenius ${ }^{1, *}$, Johan Söderberg ${ }^{2}$, Johan Hultdin' ${ }^{2}$, Marie Lindkvist ${ }^{3,4}$, Christine Brulin $^{1}$ and Kjell Grankvist ${ }^{2}$}

${ }^{1}$ Department of Nursing, Umeå University, Umeå, Sweden

${ }^{2}$ Department of Medical Biosciences, Clinical Chemistry, Umeå University, Umeå, Sweden

${ }^{3}$ Department of Statistics, Umeå University, Umeå, Sweden

${ }^{4}$ Department of Public Health and Clinical Medicine, Epidemiology and Global Health, Umeå University, Umeå, Sweden

*Corresponding author: Karin Bölenius, Department of Nursing, Umeå University, Building A, 4:th floor, 90187 Umeå, Sweden,

Phone: +46-09-7859115, Fax: +46-90-7869851,

E-mail: karin.bolenius@nurs.umu.se

Received March 14, 2012; accepted July 3, 2012

Key words: haemolysis; intervention; medical errors; primary health care; quality indicator; venous blood specimen collection.

List of abbreviations: VBSC, venous blood specimen collection; PHC, primary health care centre; Hb, haemoglobin; HI, haemolysis index; LID, laboratory identification number; OR, odds ratio. 


\begin{abstract}
Background: Venous blood specimen collection is a common health care practice that has to follow strict guidelines, non-compliance among sampling staff may compromise patient safety. We evaluated a large-scale $2 \mathrm{~h}$ educational intervention that emphasised guideline adherence to assess possible improvements of venous blood specimen collection practices.

Methods: Blood specimen haemolysis is usually caused by inadequate venous blood specimen collection and handling, reflecting overall preanalytical handling. We monitored haemolysis of serum samples with haemolysis index corresponding to $\geq 150 \mathrm{mg} / \mathrm{L}$ of free haemoglobin for specimens sent from eleven primary health care centres and analysed on a Vitros 5,1 clinical chemistry analyser before (2008, $n=6652$ samples) and after (2010, n=6121 samples) the intervention.

Results: The total percentage of haemolysed specimens was $11.8 \%$ compared to $10.5 \%$ ( $\mathrm{p}=$ 0.022) before the intervention. As groups, rural primary health care centres demonstrated a significant reduction $(\mathrm{OR}=0.744)$ of haemolysed specimens after intervention, whereas urban primary health care centres demonstrated a significant increase $(\mathrm{OR}=1.451)$ of haemolysis.
\end{abstract}

Conclusions: A large-scale $2 \mathrm{~h}$ educational intervention to make venous blood specimen collection staffs comply with guideline practices had minor effects on collection practices. Educational interventions may be effective in wards/care centres demonstrating venous blood specimen collection practices with larger deviations from guidelines. 


\section{Introduction}

Continuous improvement of health care is important to ensure quality and patient safety (1). Swedish health care staff is obliged by law to secure patient safety and it is an individual duty to be up to date with health care guidelines and work according to evidence-based and established practices (2). However, there is a gap between evidence and practice $(1,3)$ as health care staff does not always follow guidelines (4-9) and in particular are not updated with the results of new research and changed guidelines and practices (3). Difficulties in implementation of clinical guidelines and new evidence into daily practice, can lead to patients not receiving best possible care, or exposure to safety risks or adverse events (3).

Venous blood specimen collection (VBSC) is a common procedure in health care and has to be performed according to evidence-based guidelines (10). However, our studies revealed that VBSC staff compliance is poor (4-9). The vast majority of haemolysed venous blood specimens are caused by errors when the specimen is collected and handled, i.e. in the preanalytical phase performed locally at primary health care centres (PHCs) and hospital wards. This contributes to the majority of all errors in the total testing process (11-15).

Haemolysis in vitro is an important indicator of the overall quality of the preanalytical phase since it is caused primarily by inappropriate specimen collection and specimen handling, such as prolonged use of venous stasis, delayed separation of blood from plasma and blood collection through intravenous catheter $(11,13,16-19)$. The haemolysis index (HI) in automated analysers is an efficient method for detecting haemolysis (14, 20). For many years, the HI has been used in laboratories to automatically reject specimens that are haemolysed in order to avoid analytical interference.

The low preanalytical error rates noted by individual laboratories calls for large databases as well as appropriate techniques for the detection of errors and their consequent reduction. Comparisons of error rates and the effect of interventions have hitherto been 
possible (although rarely performed) only between laboratories and not between individual hospital wards or PHCs. The ability to assess the frequent "near-misses" during VBSC would allow for general and directed corrective educational interventions and also permit comparison and benchmarking of preanalytical practices between wards and PHCs (21).

We have previously shown that the percentage of haemolysed venous blood specimen [specimens with HI above $150 \mathrm{mg} / \mathrm{L}$ free haemoglobin $(\mathrm{Hb})$ ] is a proper indicator of VBSC quality useful for preanalytical quality assessment and benchmarking at the hospital ward, PHC and even at the individual phlebotomist level (12).

The County Council executive board gave permission to a short intervention including all VBSC staff with the intension to improve adherence to VBSC guidelines, and aiming to reduce costs (16) and increase patient safety. Laboratory instructors within the County Council developed and performed a large-scale short educational program focusing on rehearsal and implementation of the national and local VBSC guidelines to the individual phlebotomist. In this study we monitored the percentage of haemolysed venous blood specimens of eleven PHCs before and after the large-scale intervention to assess possible improvements of VBSC practices.

\section{Materials and methods}

\section{Study design and setting}

To determine if VBSC practices were improved after a large scale educational intervention we performed a follow-up study with a "before-after" approach. VBSC staff within the County Council including the PHCs, participated in a mandatory short educational intervention to update the knowledge of general preanalytical practices according to national and local VBSC guidelines. We collected serum samples during a three-month period before (July - September 2008, n $=6652$ specimens) and after (July - September 2010, $\mathrm{n}=6121$ specimens) the intervention, sent from all PHCs to the university laboratory where we could extract HI data and patient data. Blood specimens 
were compared from 11 PHCs sending specimens for routine analysis at the Clinical Chemistry Laboratory, Umea University Hospital, in northern Sweden.

\section{Specimen collection and determination of haemolysis}

Routine venous blood specimens were collected by needle, recommended gauge between 19 and 23 Gauge (10) in plastic $3.5 \mathrm{~mL}$ evacuated serum separator test tubes with an inert polymer gel barrier and a clot activator (Becton Dickinson, Franklin Lakes, NJ, cat-no 367957). After allowing for clotting, recommended time $30 \mathrm{~min}$, the specimens were centrifuged locally or in the laboratory for nearby PHCs. Test tubes were transported in cooled insulated boxes $\left(5-12{ }^{\circ} \mathrm{C}\right)$ twice a day from the urban, and once a day from the rural PHCs and then analysed for routine clinical chemistry analyses on Vitros 5,1 automated analysers (Ortho-Clinical Diagnostics, Inc., Rochester, NY, USA).

The analysers automatically determine HI in all blood specimens utilizing a diffraction grating and a 256-element photodiode array of which a vector dot product of the first derivative of the absorbance spectrum provides the HI. HI determination for the Vitros 5,1 was verified by serial dilution of a purified haemolysate into two serum specimens with a low degree of haemolysis. The amount of free $\mathrm{Hb}$ in these specimens was determined by a spectrophotometric assay (22) using a Perkin Elmer, Lambda 35 spectrophotometer (Waltham, MA, USA). There was a linear relationship between $\mathrm{HI}$ and the amount of free $\mathrm{Hb}$ $\left(\mathrm{R}^{2}=0.9865\right)$, and $1 \mathrm{~g} / \mathrm{L}$ of free Hb corresponded to a HI of 99.

The samples were considered haemolysed at a $\mathrm{HI} \geq 15$ (equivalent to approx. $150 \mathrm{mg} / \mathrm{L}$ free $\mathrm{Hb}$ ) which was the detection limit for the analyser. It is to note that the analytical rejection limits (set due to expected analytical interference) is much higher and vary for different analytics based on haemolysis levels set by the manufacturer and these limits were verified by the laboratory. Analytical rejection for e.g. lactate dehydrogenase and iron was at 
specimen $\mathrm{HI} \geq 50$ (approx. $500 \mathrm{mg} / \mathrm{L}$ free $\mathrm{Hb}$ ) and for e.g. potassium, alkaline phosphatase, and amino transferases at $\mathrm{HI} \geq 100$ (approx. $1000 \mathrm{mg} / \mathrm{L}$ free $\mathrm{Hb}$ ) for the instruments.

\section{The intervention}

Between January 2009 and November 2010, almost all VBSC staff in a County Council of northern Sweden participated in the intervention $(n=2171)$. Eleven PHCs, with in all 199 VBSC staff, 172 (120 registered nurses, 51 enrolled nurses, and one laboratory technician) were included in the study (Table 1).

Table 1. Numbers of staff participating in the intervention over time for each PHC

\begin{tabular}{|c|c|c|c|c|c|c|c|c|c|c|c|c|}
\hline $\begin{array}{l}\text { Year- } \\
\text { month }\end{array}$ & $\begin{array}{l}\text { PHC } \\
1\end{array}$ & $\begin{array}{l}\text { PHC } \\
2 \\
\end{array}$ & $\begin{array}{l}\text { PHC } \\
3 \\
\end{array}$ & $\begin{array}{l}\text { PHC } \\
4\end{array}$ & $\begin{array}{l}\text { PHC } \\
5 \\
\end{array}$ & $\begin{array}{l}\text { PHC } \\
6 \\
\end{array}$ & $\begin{array}{l}\text { PHC } \\
7 \\
\end{array}$ & $\begin{array}{l}\text { PHC } \\
8 \\
\end{array}$ & $\begin{array}{l}\text { PHC } \\
9 \\
\end{array}$ & $\begin{array}{l}\text { PHC } \\
10\end{array}$ & $\begin{array}{l}\text { PHC } \\
11 \\
\end{array}$ & Total \\
\hline $2009-02$ & - & - & - & - & - & - & - & - & - & - & - & 0 \\
\hline 2009-03 & - & - & 3 & - & - & 3 & - & 3 & - & - & 1 & 10 \\
\hline 2009-04 & - & - & 6 & - & - & 4 & 1 & 6 & - & 3 & 1 & 21 \\
\hline 2009-05 & 4 & - & - & - & 1 & - & - & - & - & - & - & 5 \\
\hline 2009-06 & - & - & - & - & - & - & - & - & - & - & - & 0 \\
\hline 2009-07 & - & - & - & - & - & - & - & - & - & - & - & 0 \\
\hline 2009-08 & - & - & - & - & - & - & - & - & - & - & - & 0 \\
\hline 2009-09 & 1 & - & - & 13 & - & 11 & 9 & - & - & - & - & 34 \\
\hline $2009-10$ & - & - & 12 & - & 9 & - & 21 & - & - & 4 & - & 46 \\
\hline 2009-11 & - & 3 & - & - & - & - & 3 & - & - & - & - & 6 \\
\hline $2009-12$ & - & 2 & 1 & - & - & - & - & - & - & - & - & 3 \\
\hline 2010-01 & - & - & - & - & - & - & - & - & - & - & - & 0 \\
\hline 2010-02 & - & 7 & - & - & - & - & 1 & - & - & - & - & 8 \\
\hline 2010-03 & 1 & 4 & - & - & 1 & - & 3 & - & 2 & 10 & - & 21 \\
\hline 2010-04 & 5 & - & - & - & - & - & - & - & - & - & - & 5 \\
\hline 2010-05 & 1 & 3 & - & 2 & 5 & - & - & - & - & 2 & - & 13 \\
\hline 2010-06 & - & - & - & - & - & - & - & - & - & - & - & 0 \\
\hline $2010-07^{*}$ & - & - & - & - & - & - & - & - & - & - & - & 0 \\
\hline $2010-08^{*}$ & - & - & - & - & - & - & - & - & - & - & - & 0 \\
\hline $2010-09 *$ & - & - & - & - & - & - & - & - & - & 1 & - & 1 \\
\hline $2010-10$ & - & - & - & - & - & - & 1 & - & - & - & - & 1 \\
\hline $2010-11$ & - & 7 & - & - & - & - & 1 & - & - & - & - & 8 \\
\hline 2010-12 & 3 & 3 & 4 & - & - & - & - & - & 6 & - & 1 & 17 \\
\hline $\begin{array}{l}\text { and after } \\
\text { Total }\end{array}$ & 15 & 29 & 26 & 15 & 16 & 18 & 40 & 9 & 8 & 20 & 3 & 199 \\
\hline
\end{tabular}

* Months when specimen haemolysis was monitored. 
Twenty-seven staff participated in the educational intervention after the study period and was excluded. The distribution of blood collection staff categories of the PHCs is typical for Sweden. The PHCs have similar working conditions and use the same national handbook (10). During the two-year period two neighbouring PHCs had been merged into one. The percentage of participating (with intervention) VBSC staff of individual PHCs varied from 25 to $100 \%$, PHCs number 4,5,6,8 (100\%), PHCs number 1,3,7,10 (80-99\%) and 2,9,11 (25$79 \%)$

Due to reported sub-standard VBSC practices (4-9) the County Council executive board gave permission to an educational intervention under the premises that it should be short, cheap and have minor interference with daily work. Given these conditions, the laboratory instructors performed a large-scale educational intervention including a specific lecture regarding the VBSC guideline practices according to the national handbook for health care (10) and the local directive (23), similar to international standards (24), also stressing practices important for the occurrence of haemolysis (12). For example they were updated and informed about the use of stasis, how to store and handle the test tube prior to sampling. In short, the large scale intervention included three parts: 1) it mandatory studying of the national VBSC guidelines (10) prior to education; 2) 2h lectures of which the first included VBSC practices and stressed practices important for the occurrence of haemolysis $(15-18,24-$ 30), and the second regarding collection of microbiological specimens. The first lecture also contained information regarding local non-adherence to preanalytical practices $(4-9) ; 3)$ participants were to adequately respond to five written examination questions regarding VBSC guidelines and if passed examination they received a VBSC competence certificate valid for four years. Example of examination questions are; When should the stasis be released? How many times would you reverse the test tube after sampling? For how long can the stasis be applied during sampling? For how long should the patient rest before sampling? 
The numbers of participants were $11-89$ at the lecture occasions given by hospital laboratory instructors.

\section{Analysis}

HI values and the laboratory identification number (LID) were obtained from the Vitros 5,1 analysers for all specimens. Three identical analysers were used on a rotating schedule. Information on age and sex of the patients along with the ordering unit was obtained from the laboratory information system (Flexlab 2.2.2, TietoEnator, Kista, Sweden). The data are presented as the percentage of specimens above the detection limit for the analyser $\mathrm{HI} \geq 15$, and also as the HI 95th percentile of all specimens sent from the PHC for analysis.

The haemolysis data was analysed using Chi-square for independence and MannWhitney U-tests where appropriate. Data from the laboratory information system was merged by using the corresponding LID for each analysis. Specimens with duplicate/multiple LID (specimens where more than one analysis was requested), cases with missing HI values due to machine error and a few cases with invalid patient sex and age data were excluded. The total file contained ordering PHC, specimen HI, age and sex of the patients. The PHCs were divided after distance to the laboratory; the urban group included 6 PHCs within 1-8 km from the laboratory; and the rural group included 5 PHCs within 17-86 km (12).

We used multiple logistic regression analysis mainly to explore the association between haemolysis (HI > 15) and year (before/ after intervention), with consideration for sex, age, and PHC. Odds ratios (OR), confidence intervals (CI) and p-values (p) are reported. Parameters were estimated with generalized estimating equations where blood specimens within each PHC were assumed to be correlated with an exchangeable correlation structure. The statistical significance was defined as $p<0.01$. IBM SPSS Statistics ${ }^{\circledR}$ (version 18), was used for all statistical analyses. 


\section{Ethics}

The education was mandatory and the head of the PHC gave final permission to participate in the educational intervention. The research plan was approved by the Regional Ethical Review Board (Dnr 2010-355-32M).

\section{Results}

The percentage of specimens with HI $\geq 15$ during the July to September period 2010 increased to $11.8 \%$ compared to $10.5 \% 2008(\mathrm{p}=0.022)$. The HI 95th percentile $(95 \%$ of all HI determinations below this value) increased to 22 compared to 19 ( $\mathrm{p}=0.021$, results not shown) when in total $87 \%$ of the VBSC staff of the 11 compared PHCs had participated in the intervention (Table 2).

Table 2. Percentage of haemolysed specimens ( $\mathrm{HI} \geq 15$, free $\mathrm{Hb} \geq$ approx. $150 \mathrm{mg} / \mathrm{L}$ ) and $\mathrm{HI}$ 95th percentile in 11 PHCs before (July - September 2008) and after (July - September 2010) the educational intervention

\begin{tabular}{llll|llll|l}
\hline $\begin{array}{l}\text { PHCs } \\
\text { 2008 }\end{array}$ & n1 & $\begin{array}{l}\text { HI } \geq 15 \\
(\%)\end{array}$ & HI 95th & $\begin{array}{l}\text { PHCs } \\
\mathbf{2 0 1 0}\end{array}$ & n1 & $\begin{array}{l}\text { HI } \geq 15 \\
(\%)\end{array}$ & HI 95th & P \\
\hline PHCs all & 6652 & 10.5 & 19 & PHCs all & 6121 & 11.8 & 22 & 0.022 \\
Rural & 2039 & 15.8 & 23 & Rural & 1902 & 12.8 & 22 & $0.007 * *$ \\
Urban & 4613 & 8.2 & 18 & Urban & 4219 & 11.4 & 22 & $<0.001 *$ \\
\hline 1 & 472 & 6.4 & 16 & 1 & 559 & 5.9 & 16 & 0.864 \\
2 & 713 & 7.2 & 16 & 2 & 628 & 8.3 & 19 & 0.502 \\
3 & 1223 & 7.6 & 17 & 3 & 989 & 9.7 & 21 & 0.063 \\
4 & 477 & 9.0 & 18 & 4 & 396 & 9.6 & 19 & 0.834 \\
5 & 307 & 17.6 & 24 & 5 & 363 & 12.0 & 22 & 0.059 \\
6 & 609 & 7.9 & 18 & 6 & 606 & 16.5 & 27 & $<0.001 *$ \\
7 & 1138 & 8.3 & 18 & 7 & 1089 & 13.3 & 23 & $<0.001 *$ \\
8 & 458 & 13.7 & 24 & 8 & 348 & 16.1 & 24 & 0.409 \\
9 & 362 & 13.8 & 21 & 9 & 364 & 12.1 & 21 & 0.561 \\
10 & 649 & 14.9 & 21 & 10 & 541 & 10.9 & 21 & 0.049 \\
11 & 244 & 32.0 & 34 & 11 & 238 & 24.4 & 31 & 0.080 \\
\hline
\end{tabular}

Rural = PHCs 4, 5, $9-11$, Urban $=$ PHCs 1- 3, 6-8. $\mathrm{n}^{1}$, Number of specimens; , Chi square for independence. *Significantly increased percentage of haemolysed specimens, **Significantly decreased percentage of haemolysed specimens

Two PHCs (no. 6 and 7) had significant higher percentage of haemolysed specimens 2010 compared with 2008 (Table 2) whereas the others were unaffected. When analyzed together, 
the five rural PHCs (No 4, 5, 9 - 11 located > $17 \mathrm{~km}$ from the laboratory) demonstrated a significant improvement $(\mathrm{p}=0.007)$ of the percentage of haemolysed specimens before and after intervention whereas the six urban PHCs had significantly increased haemolysis. The percentage of haemolysed specimens of the PHCs before and after the intervention is illustrated in (Figure 1).

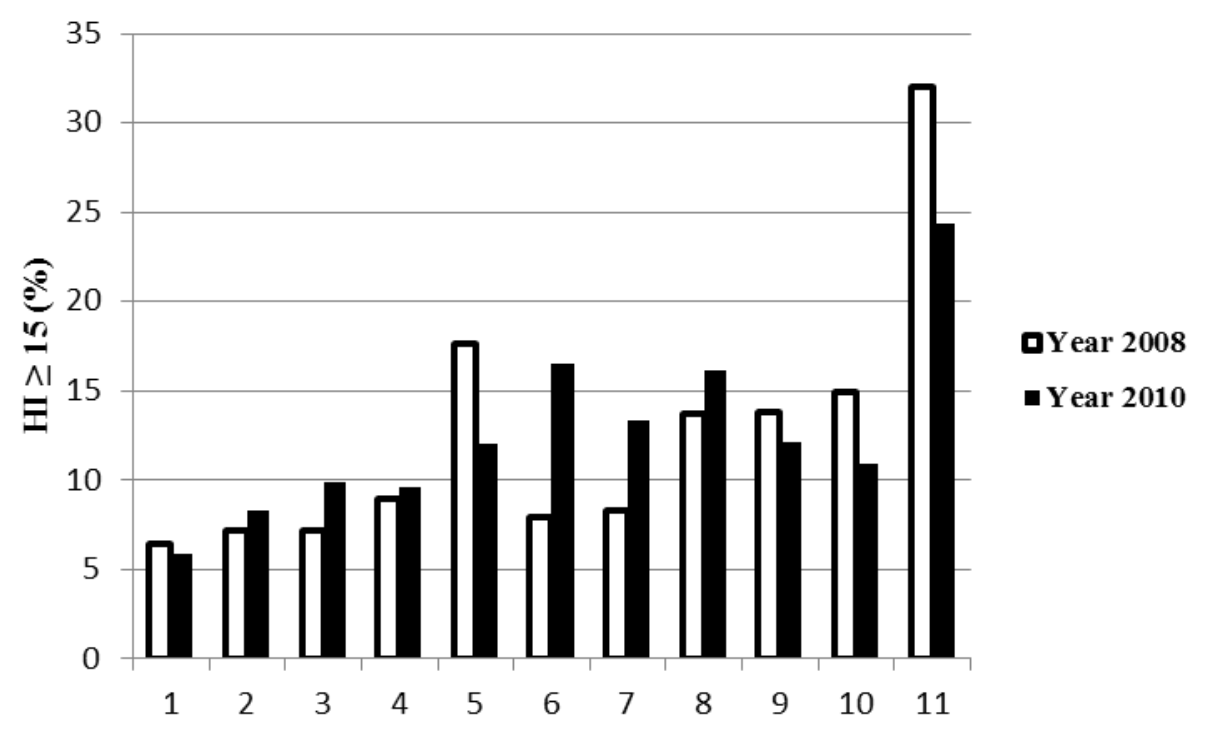

Figure 1. The percentage of haemolysed specimens before (2008), and after (2010), the intervention. Urban PHCs $(n=1-3,6-8)$ and rural PHCs $(n=4,5,9-11)$.

Due to rural PHCs higher level of haemolysed specimens before the intervention and interaction between year and PHC, further analyses were performed for location (urban/ rural) of PHCs separately. The rural PHCs (No 4, 5, 9 - 11) demonstrated a significant $(\mathrm{p}<0.001)$ reduction in haemolysis $(\mathrm{OR}=0.744, \mathrm{CI}=0.651-0.851)$ after intervention compared to before (Table 3), whereas the urban PHCs had a significant $(\mathrm{p}<0.001)$ increase $(\mathrm{OR}=1.451, \mathrm{CI}=$ $1.912-1.765$ ) in haemolysis (Table 3).

There were no improvements when comparing PHCs (No 4 - 6, 8) where all VBSC staff had participated in the intervention with PHCs (No 1, 3, 7, 10) where 80 - $99 \%$ of the staff had participated (results not shown). 
Men were significantly more likely to have haemolysed specimens than women for both rural and urban PHCs only OR for age were not significant (Table 3). The percentage of haemolysed specimens was higher for male specimens (14\%) compared to female specimens (9.6\%) and the increase of total percentage of haemolysed specimens was mainly due to the increase $(\mathrm{p}<0.001)$ from $11.6 \% 2008$ for men.

Table 3. Associations (multiple logistic regression) of sex, age, year and unit on haemolysis of rural and urban primary health care centres (PHCs). Odds ratios (OR), confidence intervals $(\mathrm{CI})$ and p-values (p) are reported. Parameters were estimated with generalized estimating equations where blood specimens within each PHC are assumed to be correlated with an exchangeable correlation structure

\begin{tabular}{|c|c|c|c|c|c|}
\hline \multicolumn{3}{|l|}{ Rural PHCs } & \multicolumn{3}{|l|}{ Urban PHCs } \\
\hline Variable & OR (CI) & $\mathbf{p}$ & Variable & OR (CI) & $\mathbf{p}$ \\
\hline $\begin{array}{l}\text { Age }(\mathrm{Md}=68, \mathrm{Q} 1=56, \\
\mathrm{Q} 3=78)\end{array}$ & $\begin{array}{l}1.004 \\
(1.001-1.008)\end{array}$ & 0.022 & $\begin{array}{l}\text { Age }(\mathrm{Md}=61, \mathrm{Q} 1=45, \\
\mathrm{Q} 3=73)\end{array}$ & $\begin{array}{l}1.002 \\
(0.998-1.006)\end{array}$ & 0.332 \\
\hline $\begin{array}{l}\text { Sex } \\
\quad \text { Women }(\mathrm{n}=2121) \\
\quad \text { Men }(\mathrm{n}=1820)\end{array}$ & $\begin{array}{l}1 \\
1.622 \\
(1.267-2.078)\end{array}$ & $<0.001$ & $\begin{array}{l}\text { Sex } \\
\quad \text { Women }(\mathrm{n}=5207) \\
\quad \text { Men }(\mathrm{n}=3625)\end{array}$ & $\begin{array}{l}1 \\
1.283 \\
(1.109-1.485)\end{array}$ & 0.001 \\
\hline $\begin{array}{r}\text { Year } \\
2008 \\
2010\end{array}$ & $\begin{array}{l}1 \\
0.744 \\
(0.651-0.851)\end{array}$ & $<0.001$ & $\begin{array}{r}\text { Year } \\
2008 \\
2010\end{array}$ & $\begin{array}{l}1 \\
1.451 \\
(1.192-1.765)\end{array}$ & $<0.001$ \\
\hline $\begin{array}{r}\text { PHC } \\
4\end{array}$ & 1 & & $\begin{array}{r}\text { PHC } \\
1\end{array}$ & 1 & \\
\hline 5 & $\begin{array}{l}1.753 \\
(1.709-1.798)\end{array}$ & $<0.001$ & 2 & $\begin{array}{l}1.301 \\
(1.277-1.324)\end{array}$ & $<0.001$ \\
\hline 9 & $\begin{array}{l}1.499 \\
(1.456-1.543)\end{array}$ & $<0.001$ & 3 & $\begin{array}{l}1.479 \\
(1.442-1.517)\end{array}$ & $<0.001$ \\
\hline 10 & $\begin{array}{l}1.509 \\
(1.479-1.538)\end{array}$ & $<0.001$ & 6 & $\begin{array}{l}2.174 \\
(2.102-2.248)\end{array}$ & $<0.001$ \\
\hline 11 & $\begin{array}{l}3.770 \\
(3.728-3.813)\end{array}$ & $<0.001$ & 7 & $\begin{array}{l}1.884 \\
(1.857-1.911)\end{array}$ & $<0.001$ \\
\hline & & & 8 & $\begin{array}{l}2.790 \\
(2.686-2.897)\end{array}$ & $<0.001$ \\
\hline
\end{tabular}

\section{Discussion}

We evaluated if the VBSC practices of the staff of 11 PHCs were improved after an educational intervention that emphasized VBSC guidelines. Our main finding was that rural 
PHCs had significantly lower percentage of haemolysed specimens (reflecting better preanalytical practices) after intervention.

Our previously result (12) showed that the prevalence of low-level haemolysed specimens is a suitable marker for preanalytical quality. The laboratory medicine profession should therefore urge instrument manufacturers to have open system for HI retrieval and to have the HI correlated to free $\mathrm{Hb}$ concentration. The $\mathrm{HI} 95^{\text {th }}$ percentile $\mathrm{HI}$ value of each PHC (preferably transformed to free $\mathrm{Hb}$ concentration for international comparability) may preferably be used and regarded as the universal " $\mathrm{HbA}_{1 \mathrm{c}}$ " of VBSC quality for laboratories, individual wards and PHCs and even of individual phlebotomists.

The short VBSC educational intervention we evaluated focused on conveying the general VBSC practices of the national guideline. We found only minor effects of the intervention despite a rather thorough before-after analysis of specimens of three months before and after the intervention, analysis of data immediately after the intervention as well as sub-analysis also according to the percentage of participating staff and staff categories.

The number of haemolysed serum specimens before and after the educational intervention significantly decreased for the rural PHCs but increased for the urban PHCs when analysed as groups. An intervention improvement is generally more probable of PHCs when starting point adherence (mild haemolysis) to recommended practice is low (31). For the individual PHCs there was little improvement or even increased percentage of haemolysed specimens after intervention. Reasons for increased number of haemolysed specimens in some PHCs after the intervention are not known. The working conditions before and after the intervention were similar and could not be explained by low participation, e.g. PHC No 6 had $100 \%$ and PHC No 7 had $95 \%$ of the VBSC staff educated.

Haemolysis in vitro is caused primarily by inappropriate specimen collection and specimen handling (32). The educational intervention focused also on patient identification 
and information search. We believe that directed interventions focusing only on leading causes of haemolysis would result in a likely reduction of haemolysed blood specimens. A directed intervention aimed at reducing haemolysis should focus on drawing blood from the antecubital fossa (32), use needles with large bore gauge > 22 (32), fully fill test-tubes (16, 32), perform VBSC by venipuncture instead of through intravenous catheters $(18,19,27,28)$, shorten the time between sampling and analysis (16), being conservative with tourniquet use $(10,23,27,32,33)$, not delaying separation of blood from plasma (23), and avoidance of muscle contraction during sampling (10).

Swedish guidelines recommend needle with bore gauge 19-23, but one study show that gauge $>22$ lead to increased haemolysis (32). Using tourniquet during VBSC is not needed in many cases, but when collecting blood from patients with difficultly punctured or small veins, trans-illumination with near-infrared light could decrease the use of tourniquet and eliminate the impact of venous stasis on haemolysis (34).

Compared to our previous study (12), the percentage of haemolysed specimens still was more common in specimens drawn from men, and the over-all increase of mildly haemolysed specimens noted was also due to an increase for male specimens. This increase could not be explained by the increase in median age of participating sampled patient, as age was not significantly increased in the multiple logistic regression model. Sex differences of haemolysis have not generally been noted in other studies $(25,26)$ with few exceptions $(35)$.

The target of the intervention comprised all VBSC staff of the whole County Council and the information thus conveyed to hospital ward as well as primary health care VBSC personnel - in all a rather complex organization with staff of several professions, qualifications and working conditions. Even though we limited our evaluation to a few PHCs, the above conditions still varies with work place and individual so that it may be difficult to prove whether the outcomes are due to the intervention or not (36). Although announced as 
mandatory for all VBSC staff, economical and personnel aspects probably also influenced staff participation at each PHC. Other circumstances that could have affected the outcome are VBSC staff turnover. Regardless of these precautions, we believe that VBSC practices are surprisingly stable within each PHC between years.

Improvement programs may include large -scale interventions $(37,38)$, which ideally should include active participation, learning and working together, action learning, and reality defined as meanings as well as facts (39). Generally, the long term results of interventions/quality improvement programs are seldom evaluated $(37,38)$. Given the preset restrictive conditions for the intervention, it was decided to be performed as an educational intervention. It felt important to expose and update all VBSC staff to the national and local guidelines even though the expectations on real changes in VBSC practices were dismal. In addition to using mildly haemolysed specimens reflecting VBSC practices and over-all preanalytical specimen handling, we also performed a questionnaire study of the selfestimated VBSC practices of VBSC staff within the County Council before and after the intervention. The results of the questionnaire study are to follow.

Modifying staffs behavior to conform more closely to practice guidelines and other recommended practices has proved to be a difficult task (40). Adoption to practice guidelines is affected by several issues, among them the way they are implemented (41). Successful implementation seem to follow when the evidence is high and the context is accessible to change with positive cultures (42), appropriate monitoring and feedback mechanisms, and when there is appropriate skilled external and/or internal facilitation of the change. Poor contexts may indeed be overcome by appropriate facilitation. When strong evidence was presented to staff, negative aspects were modified to ensure that the practices were implemented (43). Although by nature necessarily stringent, guidelines could however be modified to support various types of decision making/performing practices by different users. 
Guidelines that are easy to understand, that may easily be tried, or that does not require specific resources have a greater chance of being used (43). The Clinical and Laboratory Standards Institute (24) specifically place labelling blood collection tubes after sample collection in their guidelines, although the recommendation generally is that the tubes should be labeled in the presence of the patient (44). In this study the national guideline regarding general VBSC consisted of 10 pages and included information and point-by-point instructions (10). More attention of modifying guidelines to be focused, easy to understand and applicable should be prioritized in future research and health care.

Also, systematic use of theories in describing, planning and evaluating qualityimprovement interventions in research may influence the implementation of change and thereby the outcome (45). For instance, cognitive theories explain clinical practices in terms of health professionals' lack of relevant (evidence-based) information, incorrect expectations about the consequences of their behavior, or attributions of VBSC risks and adverse events to causes outside their control. Therefore, to change VBSC practices, it may be important to concentrate on how VBSC staff think and make decisions about their work and support effective ways of decision making, for instance by supplying detailed or modified guidelines, decision aids, and evidence-based clinical pathways and protocols (43). This article is the first to use the percentage of haemolysed blood specimens, reflecting varying preanalytical conditions, to evaluate an educational intervention for VBSC of individual health care units.

\section{Conclusions}

The high frequency of mild haemolysis determined in all specimens from individual health care units allows for quantitative analysis so that the effect of interventions on practical procedures are possible to study and makes it possible to compare and benchmark VBSC 
quality not only at the laboratory/hospital level but also down to the health care unit/hospital ward and even individual VBSC staff level.

A large-scale $2 \mathrm{~h}$ educational intervention to make VBSC staffs comply with guideline practices had minor effects on collection practices. Educational interventions may be effective in wards/care centres demonstrating VBSC practices with larger deviations from guidelines. Successful implementation of VBSC guidelines and reduction of haemolysis in specimens are probably more efficient and cost saving by developing directed interventions with repetitions instead of short general educational interventions.

\section{Acknowledgments}

This work would not have been possible without Jenny Ekman and Annika Wästerby who retrieved haemolysis data and the laboratory instructors Susanna Hermansson, Ann-Britt Lindström, Marie Backlund and Marie Lundgren who performed the educational intervention. We would like to thank the Faculty of Medicine, Umeå University, Umeå, Sweden, the Swedish National Board of Health and Welfare, Sweden and Västerbotten County Council in Sweden for research funding.

Authors' conflict of interest: The authors stated that there are no conflicts of interest regarding the publication of this article.

Authors' contributions: KB, JS, CB and KG proposed the original idea for the study. KB and $\mathrm{JH}$ collected the data and executed the statistical analyses together with ML. KB drafted the manuscript and all the authors read the manuscript critically for important intellectual content and approved the final manuscript. 


\section{References}

1. Gagliardi AR, Brouwers MC, Palda VA, Lemieux-Charles L, Grimshaw JM. An exploration of how guideline developer capacity and guideline implementability influence implementation and adoption: study protocol. Implement Sci 2009;4:36.

2. Swedish National Board of Health and Welfare. (SFS 2010:659).

Available at: http://62.95.69.3/SFSdoc/10/100659.PDF. Accessed on Mar 02, 2012.

3. Grol R, Grimshaw J. From best evidence to best practice: effective implementation of change in patients' care. Lancet 2003;362:1225-30.

4. Söderberg J, Grankvist K, Brulin C, Wallin O. Incident reporting practices in the preanalytical phase: low reported frequencies in the primary health care setting. Scand J Clin Lab Invest 2009;69:731-5.

5. Söderberg J, Wallin O, Grankvist K, Brulin C. Is the test result correct? a questionnaire study of blood collection practices in primary health care. J Eval Clin Pract 2010;16:707-11.

6. Söderberg J, Brulin C, Grankvist K, Wallin O. Preanalytical errors in primary healthcare: a quationnaire study of information search procedures, test reqest management and test tube labelling. Clin Chem Lab Med 2009;47:195-201.

7. Wallin O, Söderberg J, Van Guelpen B, Stenlund H, Grankvist K, Brulin C. Preanalytical venous blood sampling practices demand improvement - A survey of test-request management, testtube labelling and information search procedures. Clin Chim Acta 2008;391:91-7.

8. Wallin O, Söderberg J, Van Guelpen B, Stenlund H, Grankvist K, Brulin C. Blood sample collection and patient identification demand improvement: a questionnaire study of preanalytical practices in hospital wards and laboratories. Scand J Caring Sci 2010;24:581-91.

9. Wallin O. Preanalytical errors in hospitals: Implications for quality improvement of blood sample collection. [doctoral thesis]. Umeå: Umeå Universitet; 2008.

10. The Handbook for Healthcare

Available at: http://www.vardhandboken.se/In-English/. Accessed on Jan 18, 2012.

11. Lippi G, Blanckaert N, Bonini P, Green S, Kitchen S, Palicka V, et al. Haemolysis: an overview of the leading cause of unsuitable specimens in clinical laboratories. Clin Chem Lab Med 2008;46:764-72.

12. Söderberg J, Jonsson PA, Wallin O, Grankvist K, Hultdin J. Haemolysis index - an estimate of preanalytical quality in primary health care. Clin Chem Lab Med 2009;47:940-4.

13. Laga A, Cheves T, Maroto S, Coutts M, Sweeney J. The suitability of hemolyzed specimens for compatibility testing using automated technology. Transfusion 2008;48:1713-20.

14. Guder W, da Fonseca-Wollheim F, Heil W, Schmitt $Y$, Töpfer G, Wisser H, et al. The Haemolytic, Icteric and Lipemic Sample Recommendations Regarding their Recognition and Prevention of Clinically Relevant Interferences. Lab Med 2000;24:357-64. 
15. Plebani M, Piva E. Medical errors: pre-analytical issue in patient safety. J Med Biochem 2010;29:310-14.

16. Ong ME, Chan YH, Lim CS. Reducing blood sample hemolysis at a tertiary hospital emergency department. Am J Med 2009;122:1054.e1-6.

17. Kirchner MJ, Funes VA, Adzet CB, Clar MV, Escuer MI, Girona JM, et al. Quality indicators and specifications for key processes in clinical laboratories: a preliminary experience. Clin Chem Lab Med 2007;45:672-7.

18. Kennedy C, Angermuller S, King R, Noviello S, Walker J, Warden J, et al. A comparison of hemolysis rates using intravenous catheters versus venipuncture tubes for obtaining blood samples. J Emerg Nurs 1996;22:566-9.

19. Munnix IC, Schellart M, Gorissen C, Kleinveld H. Factors reducing hemolysis rates in blood samples from the emergency department. Clin Chem Lab Med 2011;49:157-58.

20. Cox SR, Dages JH, Jarjoura D, Hazelett S. Blood samples drawn from IV catheters have less hemolysis when 5-mL (vs 10-mL) collection tubes are used. J Emerg Nurs 2004;30:529-33.

21. Bölenius K, Brulin C, Grankvist K, Lindkvist M, Söderberg J. A content validated questionnaire for assessment of self reported venous blood sampling practices. BMC Res Notes 2012;5:39.

22. Kahn SE, Watkins BF, Bermes EW, Jr. An evaluation of aspectrophotometric scanning technique for measurement of plasma hemoglobin. Ann Clin Lab Sci 1981;11:126-31.

23. Västerbottens Läns Landsting. Provtagningsanvisningar Laboratoriemedicin VLL (in Swedish) Available at: https://webappl.vll.se/provtagningsanvisningar. Accessed on Mars 02, 2012.

24. Clinical and Laboratory Standards Institute: Procedures for the Collection of Diagnostic Blood Specimens by Venipuncture. Approved Standard. CLSI document H3-A6 $6^{\text {th }}$ edition. Wayne: CLSI; 2007.

25. Tanabe P, Kyriacou DN, Garland F. Factors affecting the risk of blood bank specimen hemolysis. Acad Emerg Med 2003;10:897-900.

26. Thomas L. Haemnlysis as influence \& interference factor. Biochim Clin 2002;26:95.

27. Lippi G, Salvagno GL, Montagnana M, Brocco G, Guidi GC. Influence of hemolysis on routine clinical chemistry testing. Clin Chem Lab Med 2006;44:311-6.

28. Grant MS. The effect of blood drawing techniques and equipment on the hemolysis of ED laboratory blood samples. J Emerg Nurs 2003;29:116-21.

29. Fang L, Fang SH, Chung YH, Chien ST. Collecting factors related to the haemolysis of blood specimens. J Clin Nurs 2008;17:2343-51.

30. Carraro P, Servidio G, Plebani M. Hemolyzed specimens: a reason for rejection or a clinical challenge? Clin Chem 2000;46:306. 
31. Jamtvedt G, Young JM, Kristoffersen DT, O'Brien MA, Oxman AD. Audit and feedback: effects on professional practice and health care outcomes.

Available at: http://onlinelibrary.wiley.com/doi/10.1002/14651858.CD000259.pub2/pdf Accessed on Mar 02, 2012.

32. Lippi G, Plebani M, Di Somma S,Cervellin G. Hemolyzed specimens: a major challenge for emergency departments and clinical laboratories. Crit Rev Clin Lab Sci 2011;48:143-153.

33. Lippi G, Salvagno GL, montagnana GB, Guidi GC. Influence of short-term venous stasis on clinical chemistry testing. Clin Chem Lab Med 2005;43:869-875.

34. Lima-Oliveira G, Lippi G, Salvagno GL, Montagnana M, Scartezini M, Guidi GC, et al. Transillumination: a new tool to eliminate the impact of venous stasis during the procedure for the collection of diagnostic blood specimens for routine haematological testing. Int J Lab Hematol 2011;33:457-62.

35. Ernst DJ. Flawless Phlebotomy: Becoming a great collector. Nursing 1995;25:54.

36. Ovretveit J, Gustafson D. Evaluation of quality improvement programmes. Qual Saf Health Care 2002;11:270-5.

37. Ovretveit J, Gustafson D. Improving the quality of health care - Using research to inform quality programmes. Brit Med J 2003;326:759-61.

38. Landefeld CS, Shojania KG, Auerbach AD. Should we use large scale healthcare interventions without clear evidence that benefits outweigh costs and harms? No. BMJ 2008;336:1277.

39. What are Large Scale Intervention?

Available at:

http://www.largescaleinterventions.com/english\%20version/intro\%20What\%20is\%20LSI.htm Accessed on Jan 18, 2012.

40. Mittman BS, Tonesk X, Jacobson PD. Implementing clinical practice guidelines: social influence strategies and practitioner behavior change. QRB Quality review bulletin 1992;18:413.

41. Gagliardi AR, Brouwers MC, Palda VA, Lemieux-Charles L, Grimshaw JM. How can we improve guideline use? a conceptual framework of implementability. Implement Sci 2011;6:26.

42. Fink R, Thompson CJ, Bonnes D. Overcoming barriers and promoting the use of research in practice. J Nurs Admin 2005;35:121-9.

43. Franke AL, Smit MC, de Veer AJ, Mistiaen P. Factors influencing the implementation of clinical guidelines for health care professionals: a systematic meta-review. BMC Med Inform Decis Mak 2008;8:38.

44. Lippi G, Sonntag O, Plebani M. Appropriate labelling of blood collection tubes: a step ahead towards patient's safety. Clin Chem Lab Med 2011;49:1921-23.

45. Grol RP, Bosch MC, Hulscher ME, Eccles MP, Wensing M. Planning and studying improvement in patient care: The use of theoretical perspectives. Milbank Q 2007;85:93-138. 